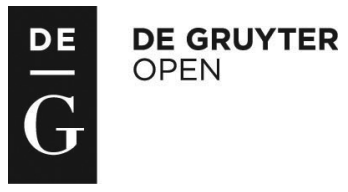

\title{
EFFECT OF PHYSICAL EXERCISE ON CORTISOL CONCENTRATION AND NEUTROPHIL OXYGEN METABOLISM IN PERIPHERAL BLOOD OF HORSES*
}

\author{
Wiesław Krumrych ${ }^{1 \star}$, Ryszard Gołda ${ }^{1}$, Marcin Gołyński², Hanna Markiewicz ${ }^{3}$, Mateusz Buzała ${ }^{4}$ \\ ${ }^{1}$ Department of Immunobiology, Institute of Experimental Biology, Kazimierz Wielki University, \\ Powstańców Wlkp. 10, 85-090 Bydgoszcz, Poland \\ ${ }^{2}$ Sub-Department of Internal Diseases of Farm Animals and Horses, Department and Clinic of Animal \\ Internal Diseases, Faculty of Veterinary Medicine, University of Life Sciences, Akademicka 13, \\ 20-950 Lublin, Poland \\ ${ }^{3}$ Laboratory of Milk Examination, Institute of Experimental Biology, Kazimierz Wielki University, \\ Powstańców Wlkp. 10, 85-090 Bydgoszcz, Poland \\ ${ }^{4}$ Department of Animal Biochemistry and Biotechnology, UTP University of Science and Technology, \\ Mazowiecka 28, 85-084 Bydgoszcz, Poland \\ •Corresponding author: krumrych@ukw.edu.pl
}

\begin{abstract}
The aim of the study was to evaluate the effect of regular physical exercise on cortisol concentration and oxygen-dependent bactericidal activity of neutrophils in peripheral blood in recreational and competitive sport horses (racehorses - Ra, trotters $-\mathrm{T}$, jumping horses $-\mathrm{J}$, driving horses - D). The study was conducted on 55 clinically healthy horses. Blood samples were collected from the external jugular vein three times: before exercise, immediately after exercise, and after 30-min rest. Blood samples were subjected to haematological examination, cortisol concentration was determined by radioimmunoassay (RIA) and neutrophil oxygen metabolism of neutrophils was determined using a chemiluminescence method. The analysis showed that cortisol concentration was significantly higher $(\mathrm{P}<\mathbf{0 . 0 5})$ post-exercise only in the blood of sport horses. This finding, along with a significant correlation $(\mathbf{P}<\mathbf{0 . 0 0 0 0 5})$ with the heart and respiratory rates, suggests that the magnitude of cortisol secretion is associated with the intensity and duration of exercise. The relatively small post-exercise increase in cortisol concentration during different exercises of horses resulted in a transient increase of chemiluminescence activity of neutrophils, mainly in $D$ $(\mathbf{P}<\mathbf{0 . 0 0 0 0 1})$ and $\mathbf{J}$ horses $(\mathbf{P}<\mathbf{0 . 0 1})$. In the studied groups analysis of the correlation between cortisol concentration and other parameters showed significant correlation only in the case of the $\mathrm{CL}$ total in $\mathrm{T}(\mathrm{P}<\mathbf{0 . 0 2})$ and $\mathrm{D}$ horses $(\mathrm{P}<\mathbf{0 . 0 0 4})$. It is therefore apparent that in a limited concentration, this hormone may stimulate the activity of these cells, although the effect of other neurohormonal factors cannot be excluded. This result confirms that regular and moderate training loads have a beneficial effect on the immunological status of horses.
\end{abstract}

Key words: horses, physical exercise, cortisol, chemiluminescence of neutrophils

*This study was supported by statutory activity. 
Physical exercise, as one of factors, elicits many non-specific adaptive reactions aimed at maintaining or restoring body homeostasis. It is accepted that the effective response of the organism is possible due to the interactions between the nervous, hormonal and immune systems (Eskandari and Sternberg, 2002). A special role in this regard is assigned to the activation of the hypothalamus-pituitary-adrenal (HPA) axis and the adrenergic system, resulting in increased release of many neurohormonal factors (e.g. adrenocorticotropic hormone - ACTH, glucocorticoids, catecholamines, $\beta$-endorphins, sex steroids) into peripheral blood (Hyyppä, 2005). One of the most widely used indicators of stress is cortisol, an adrenal cortex hormone which not only modulates carbohydrate, protein and lipid metabolism, but also affects reproductive function and immune mechanisms (Aurich and Aurich, 2008; Malinowski et al., 2006).

The widespread use of horses to perform exercise (mainly sport) tasks has made equine exercise physiology a subject of continuing interest. Much attention in this respect has been given to the study of exercise stress, using the determinations of cortisol concentrations in blood serum or plasma (Casella et al., 2016; Sabev, 2011), saliva (Kędzierski et al., 2013; Peeters et al., 2013), urine and faeces (Gorgasser et al., 2007; Toutain et al., 1995), in the context of the performance, sporting achievements (Casella et al., 2016; Marc et al., 2000; Sabev, 2011) and welfare (Houpt et al., 2001) of these animals. It is well established that magnitude of exercise-induced changes in blood cortisol concentration depends mainly on the intensity, type and duration of the training load (Desmecht et al., 1996; Jimenez et al., 1998; Thornton, 1985), as well as on the training progress, fitness (Finno et al., 2010; Marc et al., 2000) and age (Horohov et al., 1999) of the horses.

One of the consequences of increased cortisol secretion is its effect on the body's immune function. Numerous studies in the horse have demonstrated that long and exhausting physical exercise, which involves a marked, even 2- to 3-fold increase in the blood cortisol concentration (Hinchcliff et al., 2008), leads to a clear leukocytosis, a stress leukogram, which is characterized by increased neutrophil counts, and lymphopenia, which is caused by a decrease in the number of CD4+ T and NK cells (Korhonen et al., 2000; Suzuki et al., 1999). These reactions are accompanied by a temporary suppression of immunocompetent cell function, which is characterized by a reduction in the phagocytic and bactericidal activity of neutrophils and monocytes in the blood, and of lung macrophages, lower values of the neutrophil chemotactic index, impairment of lymphocyte proliferation and NK cells cytotoxic activity (Hines et al., 1996; Horohov et al., 1999; Korhonen et al., 2000; Raidal et al., 2000; Robson et al., 2003; Wong et al., 1992), as well as lower antibody titres after influenza vaccination (Folsom et al., 2001). Several studies focused their attention on the effect of short and moderate exercise on blood cortisol levels in horses suggesting a beneficial effect of these loads on the organism through stimulation of immune reactions involving neutrophils, macrophages and NK cells (Hines et al., 1996; Korhonen et al., 2000; Raidal et al., 2000).

The exercise-induced cortisol secretion and immunomodulation were generally studied in horses that compete occasionally as well as during experimental load tests. It has been demonstrated that animals living in different environmental conditions 
are also exposed to emotional stress, which may modulate neurohormonal responses to exercise (Cayado et al., 2006).

The aim of the present study was to evaluate the effect of regular physical exercise on cortisol concentration and oxygen-dependent bactericidal activity of neutrophils in peripheral blood of breeding, recreational and competitive horses.

\section{Material and methods}

The study was conducted on 55 horses aged 2 to 15 years and included: breeding horses (B), recreational horses (R), and competitive sport horses (S) representing different sports: races $-\mathrm{Ra}$, trotter races $-\mathrm{T}$, obstacle jumps $-\mathrm{J}$, and single horse driving - D (Table 1).

Table 1. The characteristics of the horses according to their use

\begin{tabular}{|c|c|c|c|c|}
\hline $\begin{array}{l}\text { Groups } \\
\text { of horses } \\
\text { (n) }\end{array}$ & $\begin{array}{l}\text { Subgroups } \\
\text { of horses } \\
\text { (n) }\end{array}$ & $\begin{array}{l}\text { Age } \\
\text { (years) }\end{array}$ & $\begin{array}{l}\text { Sex } \\
(\mathrm{n})\end{array}$ & $\begin{array}{l}\text { Breed } \\
\text { (n) }\end{array}$ \\
\hline $\begin{array}{l}\mathrm{B} \\
(12)\end{array}$ & & $\begin{array}{c}6.92 \\
(3-11)\end{array}$ & $\begin{array}{c}\text { Mares (8) } \\
\text { Stallions (4) }\end{array}$ & Half-breed (12) \\
\hline $\begin{array}{l}R \\
(8)\end{array}$ & & $\begin{array}{c}8.75 \\
(4-15)\end{array}$ & $\begin{array}{c}\text { Mares (3) } \\
\text { Geldings (5) }\end{array}$ & Half-breed (8) \\
\hline \multirow[t]{4}{*}{$\begin{array}{l}\mathrm{S} \\
(35)\end{array}$} & $\begin{array}{l}\mathrm{Ra} \\
(8)\end{array}$ & $\begin{array}{l}4.13 \\
(3-5)\end{array}$ & $\begin{array}{c}\text { Mares (3) } \\
\text { Stallions (4) } \\
\text { Geldings (1) }\end{array}$ & English Thoroughbred (8) \\
\hline & $\begin{array}{l}\mathrm{T} \\
(9)\end{array}$ & $\begin{array}{l}2.44 \\
(2-3)\end{array}$ & $\begin{array}{c}\text { Mares (6) } \\
\text { Stallions (3) }\end{array}$ & Standardbred (9) \\
\hline & $\begin{array}{l}J \\
(9)\end{array}$ & $\begin{array}{c}8.44 \\
(6-11)\end{array}$ & $\begin{array}{c}\text { Mares (2) } \\
\text { Stallions (4) } \\
\text { Geldings (3) }\end{array}$ & $\begin{array}{c}\text { Hanoverian (4) } \\
\text { KWPN (3) } \\
\text { Selle Francais (2) }\end{array}$ \\
\hline & $\begin{array}{l}\mathrm{D} \\
(9)\end{array}$ & $\begin{array}{c}7.89 \\
(5-12)\end{array}$ & $\begin{array}{c}\text { Mares (2) } \\
\text { Stallions (1) } \\
\text { Geldings (6) }\end{array}$ & $\begin{array}{l}\text { Half-breed (6) } \\
\text { KWPN (3) }\end{array}$ \\
\hline
\end{tabular}

Explanation: $\mathrm{n}$ - number of horses; $\mathrm{B}$ - breeding horses; $\mathrm{R}$ - recreational horses; $\mathrm{S}$ - sport horses; Ra - racehorses; T - trotters; J - jumping horses; D - driving horses; KWPN - Dutch Warmblood (Koninklijke Vereniging Warmbloed Paardenstamboek Nederland).

The animals came from six training centres, two recreational centres and one breeding farm in the north-western part of Poland. The data collected during an interview directly before the beginning of the research procedure, the clinical examination (rectal temperature, heart and respiratory rates, appearance of the mucous membranes, and filling time of capillary vessels) as well as the laboratory results obtained ex post indicated that the animals were healthy. They were subject to regular prophylactic treatment including deworming and vaccination against influenza and tetanus. The horses' diet was balanced in respect of energy-protein, minerals, and vitamins according to dietary requirements established for these animals (Frape, 
2010). The diets were based on hay (6 kg), crushed oat grain (4.5 kg) and Marstall Haferfrei muesli mix (1.5 kg), which met the horses' requirement for major minerals, trace minerals and vitamins, and supplemented the diet with protein and energy. The horses had permanent access to mineral supplements and water. The conditions in all studied centres were similar and met the welfare requirements of the horses.

The horses participated in a daily training programme from 6 months $(\mathrm{T})$ to several years ( $\mathrm{J}$ and $\mathrm{D})$, which depended on the type of sport discipline. Recreational animals were used in the spring-summer season on a rather irregular basis. The average time of their daily work was $2-3 \mathrm{~h}$ during which the horses were ridden mainly by young people learning to horse ride. The physical activity of control horses (B) was much more limited and consisted mainly in spending time on pastures and paddocks for 8-10 h a day. The general characteristics of the physical exercise of the horses representing different groups is presented in Table 2.

Table 2. General characteristics of exercise of horses from different groups

\begin{tabular}{|c|c|c|c|}
\hline \multirow{2}{*}{ Horses } & \multicolumn{2}{|c|}{ Time (min) } & \multirow{2}{*}{ Type of physical exercise } \\
\hline & A & B & \\
\hline $\mathrm{R}$ & $10-15$ & $55-60$ & $\begin{array}{l}\text { Walk }(10 \mathrm{~min}) \text {, trot alternated with walk }(25-30 \mathrm{~min}) \text {, gallop }(5 \mathrm{~min}) \text {, } \\
\text { trot }(5 \mathrm{~min}) \text {, walk }(10 \mathrm{~min})\end{array}$ \\
\hline \multirow[t]{4}{*}{ S } & $2-3$ & $12-15$ & $\begin{array}{l}\text { Walk }(1 \mathrm{~min}) \text {, trot }(5 \mathrm{~min}) \text {, gallop }(200 \mathrm{~m} \text { at the pace } 13-14 \mathrm{~m} / \mathrm{s}) \text {, trot } \\
(5 \mathrm{~min})\end{array}$ \\
\hline & $12-18$ & $20-30$ & $\begin{array}{l}\text { The training of driving horses included: walk }(200 \mathrm{~m}) \text {, trot }(3000 \mathrm{~m} \text { at } \\
7 \mathrm{~m} / \mathrm{s}) \text {, walk }(400 \mathrm{~m}) \text {, trot }(1,400 \mathrm{~m} \text { at } 7 \mathrm{~m} / \mathrm{s}) \text {, trot }(400 \mathrm{~m} \text { at } 11 \mathrm{~m} / \mathrm{s}) \text {, } \\
\operatorname{trot}(1,200 \mathrm{~m} \text { at } 7 \mathrm{~m} / \mathrm{s}) \text {, trot }(400 \mathrm{~m} \text { at } 11 \mathrm{~m} / \mathrm{s}) \text {, trot }(300 \mathrm{~m} \text { at } 7 \mathrm{~m} / \mathrm{s}) \text { and } \\
\text { walk }(200 \mathrm{~m})\end{array}$ \\
\hline & $20-30$ & $50-60$ & $\begin{array}{l}\text { The training included initial phase: walk, trot and gallop alternated with } \\
\text { trot (for } 10 \mathrm{~min} \text { ) and intensive phase ( } 30-40 \text { jumps over obstacles } 120 \text { - } \\
140 \mathrm{~cm} \text { high during } 20-30 \mathrm{~min})\end{array}$ \\
\hline & $30-40$ & $40-50$ & $\begin{array}{l}\text { Single-horse driving: walk }(500 \mathrm{~m}) \text {, trot }(5,000 \mathrm{~m} \text { at } 4.2 \mathrm{~m} / \mathrm{s}) \text {, walk } \\
(1,000 \mathrm{~m}) \text {, trot with three obstacles }(3,000 \mathrm{~m} \text { at } 3.9 \mathrm{~m} / \mathrm{s})\end{array}$ \\
\hline
\end{tabular}

Explanation: A - intensive phase; B - whole exercise session.

The study was carried out in summer (from July to September) in the horses' permanent home. The average air temperature during the study was $21.8 \pm 4.2^{\circ} \mathrm{C}$ whereas humidity, atmospheric pressure, and wind were 42-73\%, 1003-1015 hPa, and $2.8-5.2 \mathrm{~m} / \mathrm{s}$, respectively. The horses exercised on an even and sandy ground. The measurements of the HR (heart rate) and RR (respiratory rate) were performed through the auscultatory method using a stethoscope.

Blood samples were collected from the external jugular vein using Vacuette system three times: before exercise - I (in the stable, before saddling or harnessing and at least an hour after feeding), immediately after exercise - II, and after 30-min rest - III, which included relaxation of the horses. Every time, the blood samples were collected into three plastic tubes: $9 \mathrm{ml}$ tubes containing lithium heparin, $4 \mathrm{ml}$ containing potassium versenate $\left(\mathrm{K}_{2}\right.$ EDTA) and $9 \mathrm{ml}$ without anticoagulant. In order to eliminate the influence of the daily rhythm on the neurohormonal activity, the first 
blood samples were collected at the same time (9:00 $\pm 30 \mathrm{~min})$. Laboratory assay of whole blood was performed not later than $5 \mathrm{~h}$ after collection, which was stored at $4^{\circ} \mathrm{C}$. After centrifugation of whole blood without anticoagulant (at $1500 \mathrm{~g}$ for 10 minutes), the separated serum was transferred to empty vials and stored at $-20^{\circ} \mathrm{C}$ until analysis.

Haemoglobin ( $\mathrm{Hb}$ ) concentration, white blood cell count (WBC) and the percentage of neutrophils (N) and lymphocytes (L) were determined from the blood samples collected into $\mathrm{K}_{2}$ EDTA containing tubes. The assay of $\mathrm{Hb}$ and $\mathrm{WBC}$ was performed by a semi-automatic method using haematological analyser Sysmex F800 (TOA Medical Electronics Co. Ltd, Japan) whereas the percentage of $\mathrm{N}$ and L was determined by microscopic analysis of blood smears using May-Grünwald-Giemsa stain.

Serum was analysed for cortisol concentration after ethyl acetate extraction of the hormone from the serum by radioimmunoassay (RIA) according to the method described by Szafrańska et al. (2002). The sensitivity of the assay was $15 \mathrm{pg} / \mathrm{sample}$, and the intra-assay coefficient of variation was approximately $4 \%$.

The evaluation of neutrophil oxygen metabolism was done in whole blood (collected into tubes containing lithium heparin) using chemiluminescence (CL) with luminol (5-amino-2,3-dihydro-1,4-phthalazinedione, product no. 09253, Fluka Chemie $\mathrm{GmbH}$, Buchs, Switzerland) diluted in a $0.4 \% \mathrm{NaOH}$ solution to a concentration of $28 \mathrm{mmol} / \mathrm{L}$ (stock solution) and then diluted 20-fold in PBS (phosphate buffered saline solution, Biomed, Lublin, Poland). The assessment was performed using a Bio-Orbit 1251 Luminometer (Pharmacia LKB, Finland) by kinetic method for $40 \mathrm{~min}$ at $38.0^{\circ} \mathrm{C}$ measuring $\mathrm{CL}$ at 5 -min intervals. The results were presented as the value of $\mathrm{CL}$ integration that is area under the curve of emission against the function of time $(\mathrm{mV} / \mathrm{min})$. Blood samples were examined for spontaneous chemiluminescence (without stimulation - WS) and after stimulation by Fc receptor binding antibody and complement components, chemotactic receptor as well as extra-receptor stimulus. The following CL stimulators were used:

- opsonised zymosan (OZ): $100 \mathrm{mg}$ of zymosan (product no. Z4250, Sigma Aldrich Chemie GmbH, Steinheim, Germany) suspended in PBS solution (10 mL) and equine plasma $(10 \mathrm{~mL})$,

- N-formyl-methionyl-leucyl-phenylalanine (fMLP), product no. F-3676, Sigma Aldrich Chemie GmbH, Steinheim, Germany: $5 \mathrm{mg}$ of fMLP dissolved in $5 \mathrm{~mL}$ DMSO (dimethyl sulfoxide, product no. D2650, Sigma Aldrich, St. Louis, USA) and diluted in PBS solution to $2.28 \mu \mathrm{mol} / \mathrm{L}$, and

- phorbol myristate acetate (PMA), product no. P8139, Sigma Aldrich Chemie GmbH, Steinheim, Germany): $5 \mathrm{mg}$ of PMA dissolved in $5 \mathrm{~mL}$ of $95 \%$ ethanol and then diluted in PBS solution to $1.62 \mu \mathrm{mol} / \mathrm{L}$.

The examined sample contained: $150 \mu \mathrm{L}$ of whole blood, $100 \mu \mathrm{L}$ of $1.41 \mathrm{mmol} / \mathrm{L}$ luminol solution and $200 \mu \mathrm{L}$ PBS or $100 \mu \mathrm{L}$ PBS $+100 \mu \mathrm{L}$ of stimulator.

Because the chemiluminescence value of blood is inversely proportional to the concentration of haemoglobin $(\mathrm{Hb})$ and directly proportional to the number of neutrophils $(\mathrm{N})$ in the sample, the obtained results were corrected relating CL value to 1,000 cells. Optimisation of the results was done according to the formula taking into account the volume of the blood sample (Krumrych and Wiśniewski, 2006): 


$$
\mathrm{CL} \text { calculated }=\frac{\mathrm{CL} \text { measured } \times \mathrm{Hb}}{(\mathrm{WBC} \times \mathrm{N} \times 150) / 100}
$$

$\mathrm{Hb}$ - haemoglobin content in \% (in relation to the mean value calculated for the particular group of horses), WBC $\left(\times 10^{3} / \mu \mathrm{L}\right)$ - absolute value of white blood cells count, $\mathrm{N}$ - percentage of neutrophils in the white blood cell picture, 150 - volume of blood in $\mu \mathrm{L}$.

The obtained results are presented as arithmetic mean $(\overline{\mathrm{x}})$ and standard deviation $( \pm$ sd). Before performing the statistical analysis, we tested the residuals for normality of data distribution using the Shapiro-Wilk test. For each dependent variable, Levene's test was used to determine homogeneity of variance. To compare the preexercise values of the studied parameters, the one-way analysis of variance (ANOVA) was used. In case the variables were normally distributed, the significance of differences between groups was verified by using the post-hoc Tukey's test. When the distribution was abnormal, the Kruskal-Wallis test was used.

The effect of exercise was assessed by one-way ANOVA for repeated measures. When significant differences were found, a post-hoc analysis (the Tukey's test) was made in order to investigate between which times significant differences existed. Correlations between the studied variables were assessed using the Pearson correlation coefficients (r). Statistical significance was set at $\mathrm{P}<0.05$ in all the cases. All statistical analyses were performed using Statistica for Windows, v. 6.0 software (StatSoft Inc., Tulsa, USA).

Interaction of age, sex and breed was not significant in the case of any parameter, therefore it had been left out from the general model and results presented as pooled.

\section{Results}

The results of clinical parameters (heart rate $-\mathrm{HR}$ and respiratory rate $-\mathrm{RR}$ ) and serum cortisol concentrations in the investigated horses are presented in Table 3.

Comparison of the resting values (test I) of these parameters did not show any significant differences between the breeding $(B)$, recreation $(R)$ and sport horses (Ra, $T, J, D)$. The exercise loads resulted in a statistically significant $(\mathrm{P}<0.00001)$ increase in heart and respiratory rates in all the groups of horses except for HR in R horses (test II). This reaction was short in all the horses because both parameters clearly decreased after 30-min rest (test III).

The post-exercise changes in the values of functional parameters were paralleled by an increase in serum cortisol concentration in the horses. This hormone increased significantly in all groups of sport horses $(\mathrm{Ra}-\mathrm{P}<0.001, \mathrm{~J}-\mathrm{P}<0.005, \mathrm{~T}$ and $\mathrm{D}$ $-\mathrm{P}<0.05)$. It is worth noting at this point the persistence of increased cortisol concentration after 30-min rest in T horses, and furthermore a slight upward tendency (Ra, J and D horses), which suggests that the elevated blood level of this hormone persisted for longer. However, the exercise of $\mathrm{R}$ horses did not result in considerable changes in the concentration of cortisol, and no significant differences were found in pre-exercise cortisol values between the horse groups. 
The mean values of the leukocyte indices (WBC, L, N, N/L) during physical exercise are shown in Table 4.

Table 3. Mean values $(\overline{\mathrm{x}} \pm \mathrm{sd})$ of the functional parameters $(\mathrm{HR}, \mathrm{RR})$ and serum cortisol concentrations of horses during physical exercise

\begin{tabular}{|c|c|c|c|c|c|}
\hline \multicolumn{2}{|c|}{$\begin{array}{l}\text { Horse } \\
\text { groups }\end{array}$} & $\begin{array}{c}\text { Sampling } \\
\text { times }\end{array}$ & $\begin{array}{c}\text { HR } \\
(/ \mathrm{min})\end{array}$ & $\begin{array}{c}\text { RR } \\
(/ \mathrm{min})\end{array}$ & $\begin{array}{l}\text { Cortisol } \\
(\mathrm{ng} / \mathrm{ml})\end{array}$ \\
\hline \multicolumn{2}{|c|}{$\begin{array}{c}\mathrm{B} \\
(\mathrm{n}=12)\end{array}$} & - & $37.67 \pm 3.60$ & $17.33 \pm 3.85$ & $41.49 \pm 14.53$ \\
\hline \multicolumn{2}{|c|}{$\begin{array}{c}\mathrm{R} \\
(\mathrm{n}=8)\end{array}$} & $\begin{array}{c}\text { I } \\
\text { II } \\
\text { III }\end{array}$ & $\begin{array}{l}36.75 \pm 3.69 \\
44.00 \pm 5.66 \\
37.25 \pm 7.32\end{array}$ & $\begin{array}{l}15.25 \mathrm{a} \pm 3,99 \\
40.00 \mathrm{~b} \pm 11.61 \\
20.00 \mathrm{a} \pm 2.83\end{array}$ & $\begin{array}{l}41.85 \pm 7.01 \\
43.07 \pm 8.93 \\
38.50 \pm 7.67\end{array}$ \\
\hline $\begin{array}{l}\mathrm{S} \\
\mathrm{p} \\
\mathrm{o}\end{array}$ & $\begin{array}{c}\mathrm{Ra} \\
(\mathrm{n}=8)\end{array}$ & $\begin{array}{l}\text { I } \\
\text { II } \\
\text { III }\end{array}$ & $\begin{array}{l}36.25 \mathrm{a} \pm 10.28 \\
85.75 \mathrm{~b} \pm 15.02 \\
41.50 \mathrm{a} \pm 3.66\end{array}$ & $\begin{array}{l}18.25 \mathrm{a} \pm 4.59 \\
69.00 \mathrm{~b} \pm 11.66 \\
29.50 \mathrm{a} \pm 5.21\end{array}$ & $\begin{array}{c}39.43 \mathrm{a} \pm 8.44 \\
55.45 \mathrm{ab} \pm 13.40 \\
66.24 \mathrm{~b} \pm 14.18\end{array}$ \\
\hline $\begin{array}{l}r \\
\mathrm{t}\end{array}$ & $\begin{array}{c}T \\
(n=9)\end{array}$ & $\begin{array}{l}\text { I } \\
\text { II } \\
\text { III }\end{array}$ & $\begin{array}{l}37.11 \mathrm{a} \pm 6.49 \\
87.56 \mathrm{~b} \pm 9.58 \\
38.89 \mathrm{a} \pm 6.86\end{array}$ & $\begin{array}{l}20.22 \mathrm{a} \pm 4.84 \\
64.89 \mathrm{~b} \pm 13.97 \\
22.00 \mathrm{a} \pm 5.39\end{array}$ & $\begin{array}{l}50.24 \mathrm{a} \pm 8.19 \\
71.84 \mathrm{~b} \pm 12.83 \\
71.43 \mathrm{~b} \pm 15.32\end{array}$ \\
\hline & $\begin{array}{c}\mathrm{J} \\
(\mathrm{n}=9)\end{array}$ & $\begin{array}{l}\text { I } \\
\text { II } \\
\text { III }\end{array}$ & $\begin{array}{l}34.00 \mathrm{a} \pm 5.83 \\
76.22 \mathrm{~b} \pm 16.29 \\
39.33 \mathrm{a} \pm 9.70\end{array}$ & $\begin{array}{l}12.44 \mathrm{a} \pm 2.19 \\
80.44 \mathrm{~b} \pm 18.81 \\
21.56 \mathrm{a} \pm 8.53\end{array}$ & $\begin{array}{l}40.88 \mathrm{a} \pm 12.71 \\
61.74 \mathrm{~b} \pm 13.84 \\
64.46 \mathrm{~b} \pm 11.09\end{array}$ \\
\hline & $\begin{array}{c}D \\
(n=9)\end{array}$ & $\begin{array}{l}\text { I } \\
\text { II } \\
\text { III }\end{array}$ & $\begin{array}{c}34.44 \mathrm{a} \pm 8.53 \\
112.00 \mathrm{~b} \pm 22.16 \\
50.89 \mathrm{c} \pm 5.11\end{array}$ & $\begin{array}{c}15.33 \mathrm{a} \pm 3.16 \\
110.44 \mathrm{~b} \pm 26.13 \\
31.33 \mathrm{a} \pm 5.00\end{array}$ & $\begin{array}{c}44.23 \mathrm{a} \pm 12.72 \\
60.72 \mathrm{ab} \pm 9.51 \\
63.66 \mathrm{~b} \pm 10.07\end{array}$ \\
\hline
\end{tabular}

Explanation: $\overline{\mathrm{x}}$ - arithmetic mean; sd - standard deviation; $\mathrm{n}$ - number of horses; HR - heart rate; RR respiratory rate; $\mathrm{B}$ - breeding horses; $\mathrm{R}$ - recreational horses; $\mathrm{Ra}$ - racehorses; $\mathrm{T}$ - trotters; $\mathrm{J}$ - jumping horses; D - driving horses; I, II, III - time of blood collection (before, immediately after exercise and after 30 min rest); $\mathrm{a}, \mathrm{b}, \mathrm{c}-$ mean values differ significantly for $\mathrm{P}<0.05$ (refer to difference between I, II and III); A, B, C - mean values differ significantly for $\mathrm{P}<0.05$ (refer to differences between mean values before exercise).

Table 4. Mean values ( $\overline{\mathrm{x}} \pm \mathrm{sd}$ ) of the leukocyte indices during physical exercise of different groups of horses

\begin{tabular}{|c|c|c|c|c|c|c|}
\hline \multicolumn{2}{|c|}{$\begin{array}{l}\text { Horse } \\
\text { groups }\end{array}$} & $\begin{array}{c}\text { Sampling } \\
\text { times }\end{array}$ & $\begin{array}{l}\text { WBC } \\
(\mathrm{G} / 1)\end{array}$ & $\begin{array}{c}\mathrm{L} \\
(\mathrm{G} / 1)\end{array}$ & $\begin{array}{c}\mathrm{N} \\
(\mathrm{G} / \mathrm{l})\end{array}$ & $\mathrm{N} / \mathrm{L}$ \\
\hline \multicolumn{2}{|c|}{$\begin{array}{c}\text { B } \\
(n=12)\end{array}$} & - & $9.17 \pm 1.27$ & $3.51 \mathrm{~A} \pm 0.88$ & $5.34 \pm 0.85$ & $1.62 \pm 0.48$ \\
\hline \multicolumn{2}{|c|}{$\begin{array}{c}\mathrm{R} \\
(\mathrm{n}=8)\end{array}$} & $\begin{array}{c}\text { I } \\
\text { II } \\
\text { III }\end{array}$ & $\begin{array}{l}7.66 \pm 1.58 \\
8.05 \pm 1.49 \\
7.56 \pm 1.20\end{array}$ & $\begin{array}{r}2.16 \mathrm{~B} \pm 0.39 \\
2.70 \pm 0.68 \\
2.33 \pm 0.48\end{array}$ & $\begin{array}{l}4.70 \pm 0.97 \\
4.76 \pm 0.93 \\
4.51 \pm 0.96\end{array}$ & $\begin{array}{l}2.26 \pm 0.65 \\
1.83 \pm 0.46 \\
2.01 \pm 0.56\end{array}$ \\
\hline $\begin{array}{l}\mathrm{S} \\
\mathrm{p} \\
\mathrm{o}\end{array}$ & $\begin{array}{c}\mathrm{Ra} \\
(\mathrm{n}=8)\end{array}$ & $\begin{array}{l}\text { I } \\
\text { II } \\
\text { III }\end{array}$ & $\begin{array}{r}8.34 \pm 0.82 \\
10.25 \pm 1.21 \\
8.94 \pm 1.15\end{array}$ & $\begin{array}{r}2.92 \mathrm{aAB} \pm 0.34 \\
5.10 \mathrm{~b} \pm 0.58 \\
3.37 \mathrm{a} \pm 0.65\end{array}$ & $\begin{array}{l}4.97 \pm 0.59 \\
4.70 \pm 0.67 \\
5.15 \pm 0.70\end{array}$ & $\begin{array}{l}1.72 \pm 0.25 \\
0.92 \pm 0.12 \\
1.56 \pm 0.27\end{array}$ \\
\hline \multirow[t]{3}{*}{$\mathrm{t}$} & $\begin{array}{c}\mathrm{T} \\
(\mathrm{n}=9)\end{array}$ & $\begin{array}{l}\text { I } \\
\text { II } \\
\text { III }\end{array}$ & $\begin{array}{r}8.86 \pm 1.43 \\
10.21 \pm 1.79 \\
8.80 \pm 1.50\end{array}$ & $\begin{array}{r}3.45 \mathrm{aAB} \pm 0.84 \\
4.75 \mathrm{~b} \pm 1.02 \\
3.64 \mathrm{ab} \pm 0.72\end{array}$ & $\begin{array}{l}5.07 \pm 0.87 \\
5.07 \pm 1.12 \\
4.82 \pm 0.88\end{array}$ & $\begin{array}{l}1.52 \pm 0.36 \\
1.09 \pm 0.25 \\
1.34 \pm 0.22\end{array}$ \\
\hline & $\begin{array}{c}\mathrm{J} \\
(\mathrm{n}=9)\end{array}$ & $\begin{array}{c}\text { I } \\
\text { II } \\
\text { III }\end{array}$ & $\begin{array}{l}7.70 \pm 1.89 \\
9.13 \pm 2.30 \\
8.18 \pm 2.59\end{array}$ & $\begin{array}{r}2.24 \mathrm{~B} \pm 0.86 \\
3.13 \pm 1.09 \\
2.31 \pm 0.78\end{array}$ & $\begin{array}{l}5.11 \pm 1.94 \\
5.60 \pm 2.44 \\
5.50 \pm 2.56\end{array}$ & $\begin{array}{l}2.89 \pm 2.09 \\
2.30 \pm 2.28 \\
2.82 \pm 2.02\end{array}$ \\
\hline & $\begin{array}{c}D \\
(n=9)\end{array}$ & $\begin{array}{c}\text { I } \\
\text { II } \\
\text { III }\end{array}$ & $\begin{array}{l}7.31 \pm 1.50 \\
8.77 \pm 2.09 \\
8.37 \pm 1.59\end{array}$ & $\begin{array}{r}2.43 \mathrm{aAB} \pm 0.61 \\
3.83 \mathrm{~b} \pm 0.93 \\
2.99 \mathrm{ab} \pm 0.94\end{array}$ & $\begin{array}{l}4.48 \pm 1.01 \\
4.46 \pm 1.27 \\
4.93 \pm 0.82\end{array}$ & $\begin{array}{l}1.91 \pm 0.50 \\
1.18 \pm 0.29 \\
1.79 \pm 0.64\end{array}$ \\
\hline
\end{tabular}

Explanation: WBC - white blood cell count; L - lymphocytes; $\mathrm{N}$ - neutrophils; N/L - N to L ratio; $\bar{x}, \mathrm{sd}, \mathrm{n}$, B, R, Ra, T, J, D, I, II, III, a, b, A, B - as in Table 3. 
The statistical analysis of the resting (pre-exercise) values of these parameters showed a significantly greater $(\mathrm{P}<0.05)$ number of lymphocytes $(\mathrm{L})$ in the blood of breeding horses (B) compared to $\mathrm{R}$ and $\mathrm{J}$ horses. Also for these cells only, a significant increase in their number was observed immediately after the exercise of sport horses $(\mathrm{Ra}-\mathrm{P}<0.001, \mathrm{~T}-\mathrm{P}<0.01, \mathrm{D}-\mathrm{P}<0.05)$ with a marked tendency for $\mathrm{L}$ to decrease to the pre-exercise values after 30 min rest. No significant differences in the WBC, N, N/L were found in the other horses, although there was a short-term tendency for post-exercise increase in WBC and a decrease of N/L in S and R horses.

The results for neutrophil chemiluminescence (CL) activity in the horse groups are shown in Table 5.

Table 5. Mean values $(\overline{\mathrm{x}} \pm \mathrm{sd})$ of spontaneous, stimulated and total chemiluminescence indices in the course of physical exercise of different groups of horses

\begin{tabular}{|c|c|c|c|c|c|c|}
\hline $\begin{array}{l}\text { Horse } \\
\text { groups }\end{array}$ & $\begin{array}{c}\text { Sampling } \\
\text { times }\end{array}$ & $\begin{array}{l}\text { CL-WS } \\
(\mathrm{mV} / \mathrm{min})\end{array}$ & $\begin{array}{c}\mathrm{CL}-\mathrm{OZ} \\
(\mathrm{mV} / \mathrm{min})\end{array}$ & $\begin{array}{l}\text { CL-fMLP } \\
\text { (mV/min) }\end{array}$ & $\begin{array}{l}\text { CL-PMA } \\
(\mathrm{mV} / \mathrm{min})\end{array}$ & $\begin{array}{l}\text { CL total } \\
(\mathrm{mV} / \mathrm{min})\end{array}$ \\
\hline $\begin{array}{c}B \\
(n=12)\end{array}$ & - & $359 \pm 132$ & $1941 \mathrm{~A} \pm 332$ & $753 \pm 204$ & $722 \pm 214$ & $3775 \mathrm{~A} \pm 499$ \\
\hline $\begin{array}{c}\mathrm{R} \\
(\mathrm{n}=8)\end{array}$ & $\begin{array}{l}\text { I } \\
\text { II } \\
\text { III }\end{array}$ & $\begin{array}{l}389 \pm 144 \\
407 \pm 149 \\
462 \pm 166\end{array}$ & $\begin{array}{r}2184 \mathrm{AB} \pm 564 \\
1863 \pm 334 \\
2064 \pm 770\end{array}$ & $\begin{array}{l}747 \pm 129 \\
791 \pm 246 \\
882 \pm 384\end{array}$ & $\begin{array}{l}791 \pm 160 \\
835 \pm 172 \\
968 \pm 288\end{array}$ & $\begin{array}{r}4111 \mathrm{AB} \pm 709 \\
3895 \pm 539 \\
4375 \pm 1113\end{array}$ \\
\hline $\begin{array}{lc}\mathrm{S} & \mathrm{Ra} \\
\mathrm{p} & (\mathrm{n}=8) \\
\mathrm{o} & \end{array}$ & $\begin{array}{l}\text { I } \\
\text { II } \\
\text { III }\end{array}$ & $\begin{array}{l}560 \pm 113 \\
733 \pm 172 \\
555 \pm 163\end{array}$ & $\begin{array}{c}2644 \mathrm{ABC} \pm 355 \\
3208 \pm 494 \\
2798 \pm 344\end{array}$ & $\begin{array}{l}829 \pm 232 \\
980 \pm 331 \\
877 \pm 290\end{array}$ & $\begin{array}{r}1087 \pm 268 \\
1299 \pm 385 \\
961 \pm 292\end{array}$ & $\begin{array}{r}5119 \mathrm{AB} \pm 589 \\
6220 \pm 672 \\
5190 \pm 728\end{array}$ \\
\hline $\begin{array}{cc}\mathrm{r} & \mathrm{T} \\
\mathrm{t} & (\mathrm{n}=9)\end{array}$ & $\begin{array}{l}\text { I } \\
\text { II } \\
\text { III }\end{array}$ & $\begin{array}{l}527 \pm 100 \\
694 \pm 152 \\
628 \pm 160\end{array}$ & $\begin{array}{c}2713 \mathrm{ABC} \pm 416 \\
3383 \pm 555 \\
355 \pm 4571\end{array}$ & $\begin{array}{l}741 \pm 193 \\
798 \pm 198 \\
770 \pm 158\end{array}$ & $\begin{array}{r}838 \pm 167 \\
1129 \pm 163 \\
967 \pm 213\end{array}$ & $\begin{array}{r}4819 \mathrm{AB} \pm 548 \\
6004 \pm 644 \\
5919 \pm 697\end{array}$ \\
\hline $\begin{array}{c}\mathrm{J} \\
(\mathrm{n}=9)\end{array}$ & $\begin{array}{l}\text { I } \\
\text { II } \\
\text { III }\end{array}$ & $\begin{array}{l}642 \pm 385 \\
970 \pm 411 \\
755 \pm 365\end{array}$ & $\begin{array}{c}3243 \mathrm{aBC} \pm 920 \\
4426 \mathrm{~b} \pm 725 \\
3769 \mathrm{ab} \pm 984\end{array}$ & $\begin{array}{l}746 \pm 368 \\
996 \pm 430 \\
933 \pm 522\end{array}$ & $\begin{array}{l}1164 \pm 412 \\
1523 \pm 647 \\
1329 \pm 434\end{array}$ & $\begin{array}{r}5796 \mathrm{aB} \pm 1968 \\
7915 \mathrm{~b} \pm 1910 \\
6786 \mathrm{ab} \pm 2074\end{array}$ \\
\hline$\underset{(n=9)}{D}$ & $\begin{array}{l}\text { I } \\
\text { II } \\
\text { III }\end{array}$ & $\begin{array}{r}607 \mathrm{a} \pm 196 \\
1057 \mathrm{~b} \pm 324 \\
873 \mathrm{ab} \pm 206\end{array}$ & $\begin{array}{r}3484 \mathrm{aC} \pm 685 \\
5875 \mathrm{~b} \pm 813 \\
4828 \mathrm{c} \pm 507\end{array}$ & $\begin{array}{r}821 a \pm 274 \\
1365 b \pm 637 \\
917 a b \pm 316\end{array}$ & $\begin{array}{r}974 \mathrm{a} \pm 226 \\
1606 \mathrm{~b} \pm 356 \\
1528 \mathrm{~b} \pm 361\end{array}$ & $\begin{array}{c}5885 \mathrm{aB} \pm 1063 \\
9903 \mathrm{~b} \pm 1497 \\
8146 \mathrm{~b} \pm 649\end{array}$ \\
\hline
\end{tabular}

Explanation: CL - area under the curve of light emission in the function of time (40 min); WS - without stimulation; OZ - opsonised zymosan; fMLP - N-formyl-methionyl-leucyl-phenylalanine; PMA - phorbol myristate acetate; CL total - CL-WS + CL-OZ + CL-fMLP + CL-PMA; $\bar{x}$, sd, n, B, R, Ra, T, J, D, I, II, III, a, b, A, B, C - as in Table 3.

We found that the pre-exercise spontaneous CL activity (CL-WS) was characterized by a relatively low emission. Analysis of the CL values of cells activated by the different stimulators showed that opsonised zymosan (CL-OZ) was the most effective as it induced about a 5-fold higher CL activity of neutrophils compared to CL-WS. The other stimulators (CL-fMLP, CL-PMA) were clearly less effective. Comparison of the pre-exercise measurements of the investigated horses showed that CL activity of neutrophils was slightly higher in sport horses than in less active horses (B and R). Statistical analysis only confirmed significant differences between the mean resting values for $\mathrm{CL}-\mathrm{OZ}$ and $\mathrm{CL}$ total, showing that these parameters were higher in $\mathrm{J}(\mathrm{CL}-\mathrm{OZ}-\mathrm{P}<0.001, \mathrm{CL}$ total $-\mathrm{P}<0.02)$ and $\mathrm{D}(\mathrm{CL}-\mathrm{OZ}-0.00001$, 
CL total $-\mathrm{P}<0.01$ ) compared to $\mathrm{B}$ horses. As opposed to $\mathrm{R}$ horses, a single session of physical exercise caused an increase in neutrophil CL activity in sport horses. This reaction occurred for all the parameters, but it was statistically confirmed only for D $(\mathrm{P}<0.00001)$ and partly for $\mathrm{J}(\mathrm{P}<0.01)$ horses $(\mathrm{CL}-\mathrm{OZ}$ and $\mathrm{CL}$ total $)$. The exerciseinduced stimulation of neutrophil CL activity in the investigated animals was of short duration, because the results recorded after $30 \mathrm{~min}$ followed a downward trend towards the pre-exercise values.

The correlation analysis showed a significant relationship between most of the functional and blood parameters of the horses (Table 6).

Table 6. Coefficient of correlation (r) between functional and blood parameters of horses

\begin{tabular}{|c|c|c|c|c|c|c|c|c|}
\hline & Cortisol & HR & RR & WBC & $\mathrm{L}$ & $\mathrm{N}$ & $\mathrm{N} / \mathrm{L}$ & CL total \\
\hline Cortisol & & $0.35^{*}$ & $0.34 *$ & 0.15 & $0.25 *$ & 0.03 & -0.10 & $0.36^{*}$ \\
\hline HR & $0.35 *$ & & $0.85^{*}$ & $0.23 *$ & $0.49 *$ & -0.10 & $-0.29 *$ & $0.61 *$ \\
\hline RR & $0.34 *$ & $0.85 *$ & & $0.21 *$ & $0.40^{*}$ & -0.06 & $-0.21 *$ & $0.57 *$ \\
\hline WBC & 0.15 & $0.23 *$ & $0.21 *$ & & $0.60 *$ & $0.77 *$ & 0.14 & $-0.20 *$ \\
\hline $\mathrm{L}$ & $0.25 *$ & $0.49 *$ & $0.40 *$ & $0.60 *$ & & 0.01 & $-0.64 *$ & 0.11 \\
\hline $\mathrm{N}$ & 0.03 & -0.10 & -0.06 & $0.77 *$ & 0.01 & & $0.66^{*}$ & $-0.33 *$ \\
\hline $\mathrm{N} / \mathrm{L}$ & -0.10 & $-0.29 *$ & $-0.21 *$ & 0.14 & $-0.64 *$ & $0.66^{*}$ & & $-0.24 *$ \\
\hline CL total & $0.36^{*}$ & $0.61 *$ & $0.57 *$ & $-0.20 *$ & 0.11 & $-0.33 *$ & $-0.24 *$ & \\
\hline
\end{tabular}

Explanation: * - values of statistically significant $(\mathrm{P}<0.05)$.

We found a positive correlation between serum cortisol concentration and parameters that show high variation during the exercise (HR $-\mathrm{P}<0.00002, \mathrm{RR}-$ $\mathrm{P}<0.00005)$, $C L$ total $(\mathrm{P}<0.00001)$ and the number of lymphocytes $(\mathrm{P}<0.003)$. No significant relationship was observed between the concentration of this hormone and the WBC, N, N/L. In the studied groups analysis of the correlation between cortisol concentration and other parameters showed significant correlation only in case of the $\mathrm{CL}$ total in $\mathrm{T}(\mathrm{r}=0.4431, \mathrm{P}<0.02)$ and $\mathrm{D}$ horses $(\mathrm{r}=0.5313, \mathrm{P}<0.004)$.

\section{Discussion}

The possible overexertion of horses subjected to widely different exercise loads raises concerns for their safety and welfare. It is therefore essential to make a proper assessment of the endurance and adaptation of these animals to the applied workloads. Because physical exercise can induce stress reactions, much attention has been focused on determining the concentration of cortisol, which is commonly known as a "stress hormone".

Analysis of the mean resting values of blood cortisol concentrations in the investigated horses showed that they were within the physiologically normal range for clinically healthy horses (Nachreiner et al., 2015). No significant differences were found, however, between the animals used for breeding, recreation and sports. This 
finding suggests that the type of horse use does not determine the resting level of this hormone, which is consistent with the earlier research on sport horses used in different sport disciplines (Linden et al., 1991) and horses subjected to different training programmes (Mircean et al., 2007).

As a result of physical exercise, the specific characteristics and intensity of which were determined by the type of sport discipline, a relatively small but significant increase in serum cortisol concentration was only observed in sport horses (Ra, T, $\mathrm{J}, \mathrm{D})$. It is worth noting that the magnitude of this reaction was similar despite the varying duration of the loads (about 15-30 min in Ra and T; about 50 min in $\mathrm{J}$ and $\mathrm{D}$ horses). It is likely that the main determinant of this result was the difference in exercise intensity (highest in $\mathrm{Ra}$ and $\mathrm{T}$ horses). However, no significant increase in cortisol secretion was established after the exercise of the recreational horses (R). This result appears to be related to the clearly smaller exercise load of these animals, which is indicated by the results of clinical tests. This has been suggested by Thornton (1985), who believes that a significant post-exercise increase in blood cortisol concentration in horses may occur only when the load is high enough.

Although, the cortisol secretion from the adrenal glands during and after physical exercise has been extensively described (Casella et al., 2016; Nagata et al., 1999), it is important to study the different cortisol response patterns depending on the duration, intensity and type of exercise in athletic horses (Jimenez et al., 1998; Nagata et al., 1999; Thornton, 1985). In general, the highest (even several-fold) increases in blood and saliva cortisol concentrations were observed in horses as a result of longdistance endurance rides and three-day events (Linden et al., 1991; Miyashiro et al., 2012; Strzelec et al., 2011). It is stressed, however, that the extent to which plasma cortisol concentration increases reflects more the duration than the intensity of exercise (Linden et al., 1991; Vincze et al., 2010). It is well stated that the blood cortisol concentration showed an increase immediately after physical exercise, reaching the maximum value after 5-30 minutes (Malinowski et al., 2006; Marc et al., 2000). It has been observed that the relatively short increase post-exercise was followed by a gradual decrease in blood cortisol concentration and its rate being dependent on the type of load.

After a short effort the resting (pre-exercise) level is recovered within 40-60 min (Malinowski et al., 2006), and following long and exhaustive loads, the recovery takes much longer, but generally stabilizes within $24 \mathrm{~h}$ of the effort (Hyyppä, 2005; Mircean et al., 2007). Unfortunately our findings, although they correspond with the observations of the above authors, did not allow us to determine how long the post-exercise increase in serum cortisol concentration persisted in the sport horses because after 30 min this tendency was still recorded in Ra, J and D horses. Therefore, it seems expedient to conduct similar studies for a longer time, also in animals subjected to a moderate exercise programme.

Moreover, the degree of cortisol secretion in response to exercise in the horse depends on other factors including the training (Cayado et al., 2006; Hyyppä, 2005; Marc et al., 2000; Miyashiro et al., 2012; Nogueira et al., 2002; Sabev, 2011) and the age (McKeever, 2003) of the animals. The studies cited above clearly show that in the case of the same exercise loads, less experienced (poorly trained) and 
young horses are characterized by higher blood cortisol level post-exercise compared to older animals and those with greater training experience (Fazio et al., 2014).

It is well known that horses performing exercise tasks are also subjected to the influence of emotional stress (Bazzano et al., 2016) including environmental factors, rivalry, rider presence, which generally increases the degree of HPA axis involvement (Cayado et al., 2006; Peeters et al., 2013).

The exercise-induced secretion of cortisol in the sport horses was paralleled by a small (statistically non-significant) increase in WBC. This reaction is consistent with the results of many earlier studies, which pointed to the increase in the number and changes in the distribution of circulating leukocytes as a result of physical effort, with the magnitude of leukocytosis being associated with effort intensity and duration (Bayly, 1987; Iversen et al., 1994; Jensen-Waern et al., 1999; McCarthy and Dale, 1988; Krumrych, 2006). It is thought that this phenomenon should be termed pseudoleukocytosis, because instead of being related to the production of new cells it results from the shift (release) of all lymphocyte subpopulations into the vascular bed from the spleen, lymph nodes and bone marrow due to increased secretion of catecholamines (Iversen et al., 1994; Jensen-Waern et al., 1999; Pedersen and Hoffman-Goetz, 2000). The increase in lymphocyte count was found to be much smaller during moderate training exercise and when horses are excited before the race compared to after the race or intensive training (Rossdale et al., 1982). Our results correspond with the above observations, because sport horses ( $\mathrm{Ra}, \mathrm{T}$ and $\mathrm{D}$ ) showed a clearly higher (statistically significant) post-exercise increase in lymphocyte count compared to recreational animals.

The observations of horses subjected to long and exhausting exercise loads demonstrated that leukocytosis may occur in two phases (Bayly, 1987; Iversen et al., 1994; Korhonen et al., 2000). After a transient increase in leukocyte count as a result of lymphocytosis, WBC was found to increase again along with a mild lymphopenia, a marked prolonged neutrophilia and a marked persistent neutrophilia (Iversen et al., 1994; McCarthy and Dale, 1988). The change in leukocyte kinetics, which is manifested by an increase in the N/L ratio, is thought to be associated with increased blood cortisol concentration (Jensen-Waern et al., 1999; Robson et al., 1999), because this hormone was found not only to stimulate production of neutrophils in the bone marrow and their release into the blood, and to inhibit the migration of these cells into the tissues, but also to suppress the number of circulating lymphocytes (Pyne, 1994; Shinkai et al., 1996). It is of note that the most pronounced post-exercise neutrophilia was only observed during the post-exercise phase, after one (Robson et al., 1999; Korhonen et al., 2000) or several hours (Rossdale et al., 1982). The effect of cortisol on the proportion of leukocyte subpopulations is confirmed by studies which showed that intravenously administered corticosteroids cause lymphocytopenia, monocytopenia and neutrophilia in humans, reaching maximum values $4 \mathrm{~h}$ after injection (Pedersen and Hoffman-Goetz, 2000). The number of leukocytes usually returns to initial values within $24 \mathrm{~h}$, with lymphocytes returning to the initial state more quickly than neutrophils (Bayly, 1987). Unfortunately, the results presented above fail to answer whether the exercise of horses used for different purposes could induce the second 
phase of leukocytosis, because of the substantially shorter observation time provided in the study design.

Comparison of the resting chemiluminescence (CL) activity of neutrophils in the investigated horses showed that $\mathrm{B}$ and $\mathrm{R}$ animals were characterized by lower (spontaneous and stimulated) CL values compared to sport horses, although these differences were not always significant. This suggests a relationship with regular physical activity, the intensity and duration of which could determine the resting pro-oxidative potential of these cells. Furthermore, the differences in the resting CL values could be determined by the effect of endogenous factors, such as training progress, age, sex and breed of animals (Smith et al., 1990). Unfortunately, it was not possible to eliminate their possible impact because of the specific characteristics of using the different groups of the investigated horses. Nonetheless, the results obtained correspond with the findings of Escribano et al. (2002, 2005), who showed significantly higher resting aerobic metabolism of neutrophils and higher phagocytic activity of neutrophils in horses subjected to a moderately intensive training programme compared to untrained horses. A similar effect of training on the indicators of nonspecific immunity was reported in humans (Pyne, 1994). It should be stressed that after long and exhausting training programmes, a reverse phenomenon, namely a transient impairment of the function of peripheral blood neutrophils was observed (Hines et al., 1996; Raidal et al., 2000).

A transient increase in spontaneous and stimulated CL of neutrophils was established as a result of the physical exercise of sport horses. The differences in the dynamics of this reaction in the different groups of these animals may suggest that it is associated with the type, intensity and duration of the exercise. This is indicated by a significant increase of CL in D horses, which were subjected to relatively long and intensive loads, as reflected by the highest post-exercise increase in the HR and RR. However, this reaction was not statistically significant in $\mathrm{Ra}$ and $\mathrm{T}$ horses, the exercise load of which was shortest (12-15 and 20-30 min, respectively). These observations are also confirmed by the lack of significant changes in CL values in $\mathrm{R}$ horses, which were subjected to relatively low exercise loads. The increased CL of neutrophils, recorded in our study post-exercise, is consistent with the results of earlier studies with horses (Adamson and Slocombe, 1995; Chiaradia et al., 1998; Korhonen et al., 2000), although according to Korhonen et al. (2000) it may be the consequence of post-exercise neutrophilia. While we do not question the accuracy of this observation, our research provides evidence that physical exercise modulates the CL activity of these cells, because the results were adjusted to 1000 neutrophils and also the number of these cells did not increase in the blood of the investigated horses. It seems that one of the factors modulating the functional activity of neutrophils is the intensity of exercise. This is suggested by the findings of Raidal et al. (2000), who showed that moderate exercise of $30-40 \% \mathrm{VO}_{2 \max }$ increases the CL and phagocytic activity of neutrophils, whereas intensive exercise $\left(115 \% \mathrm{VO}_{2 \text { max. }}\right)$ causes a transient weakening of these functions in horses. These results correspond with the observations of Adamson and Slocombe (1995) and Wong et al. (1992), who recorded an impairment in the functional activity of neutrophils as a result of short but intensive exercise tests on a treadmill. Similar observations were provided by the 
results of many studies with humans (Pedersen and Hoffman-Goetz, 2000; Robson et al., 1999).

In addition to exercise intensity, the activity of neutrophils is also modified by exercise duration (Robson et al., 1999). According to Lewicki et al. (1987), an effort shorter than $30 \mathrm{~min}$ has no significant effect on oxygen-dependent bactericidal functions of these cells. This appears to be confirmed by the observations of horses subjected to several-minute exercise of moderate intensity (Escribano et al., 2005), as well as our own results obtained for R, Ra and T horses. For slightly longer loads ( $\mathrm{J}$ and $\mathrm{D}$ horses) a significant increase in CL was observed. In turn, many literature references point to suppression of neutrophil CL activity in horses as a result of prolonged endurance exercise during 80-120 km rides (Jensen-Waern et al., 1999; Robson et al., 1999). It is thought that this phenomenon is mainly determined by a relatively high increase in blood cortisol concentration immediately after the exercise (Reichlin, 1993; Wong et al., 1992), for the high doses of hydrocortisone were found to inhibit the expression of the complement receptors CR1 and CR3, leading to a reduction of phagocytic activity and intensity of the respiratory burst of neutrophils (Forslid and Hed, 1982). The consequence of the increased cortisol secretion into the blood is also the frequently observed post-exercise neutrophilia, associated with the release of immature cells with limited phagocytic function from the bone marrow (Pyne, 1994; Robson et al., 1999). It is of note that a certain role in the exercise-induced modulation of neutrophil function can also be played also by other neurohormonal factors, such as catecholamines, the growth hormone, testosterone, estrogen, and $\beta$-endorphins (Hines et al., 1996; Pedersen and Hoffman-Goetz, 2000; Suzuki et al., 1999). It is believed in this context that the immunosuppresion induced by exhausting physical exercise increases together with its intensity and duration, whereas moderate exercise is generally related to the enhancement of the immune response and better resistance to disease (Art and Lekeux, 2005; Korhonen et al., 2000; Raidal et al., 2000).

In summary, the results obtained showed a significant positive correlation between blood cortisol concentration and the HR and RR, which confirms the relationship between the magnitude of cortisol secretion and physical exercise intensity and duration. The relatively small post-exercise increase in cortisol concentration in different groups of horses resulted in a transient increase in the oxygen-dependent bactericidal activity of neutrophils. Therefore, it seems that small increase cortisol concentration may stimulate the activity of these cells, thus strengthening the body's defences, although the effect of other neurohormonal factors cannot be excluded. This finding confirms the beneficial effect of regular and moderate training loads on the immunological status of horses.

\section{References}

A d a m s o n E.J., S l o c o m b e R.F. (1995). Flow cytometric studies of equine phagocytes following strenuous exercise. Equine Vet. J., 18 (Suppl.): 37-42.

Art T., Lekeux P. (2005). Exercise-induced physiological adjustments to stressful conditions in sports horses. Livest. Prod. Sci., 92: 101-111. 
A urich C., A urich J.E. (2008). Effects of stress on reproductive functions in the horse. Pferdeheilkunde, 24: 99-102.

B a y 1 y W.M. (1987). The interpretation of clinicopathologic data from the equine athlete. Vet. Clin. North Am. Equine Pract., 3: 631-647.

Bazzano M., Giudice E., Rizzo M., Congiu F., Zumbo A., Arfuso F., Di Pietro S., B ruschetta D., P i c ci on e G. (2016). Application of a combined global positioning and heart rate monitoring system in jumper horses during an official competition - a preliminary study. Acta Vet. Hung., 64: 189-200.

Casella S., Vazzana I., Giudice E.W., Fazio F., Piccione G. (2016). Relationship between serum cortisol levels and some physiological parameters following reining training session. Anim. Sci. J., 87: 729-735.

Ca ya do P., Muñoz-Escassi B., Domínguez C., Manley W., Olabarri B., Sánchez d e la Muela M., C a stej on F., M a r a ñ on G., Var a E. (2006). Hormone response to training and competition in athletic horses. Equine Vet. J., 36 (Suppl.): 274-278.

Chiaradia E., Avellini L., Rueca F., Spaterna A., Porciello F., Antonioni M.T., Gaiti A. (1998). Physical exercise, oxidative stress and muscle damage in racehorses. Comp. Biochem. Physiol. B., 119: 833-836.

Desmecht D., Linden A., A mory H., Art T., Lekeux P. (1996). Relationship of plasma lactate production to cortisol release following completion of different types of sporting events in horses. Vet. Res. Commun., 20: 371-379.

E s crib a no B.M., A güer a E.I., Vivo R., S a n t isteban R., Castejón F.M., Rubio M.D. (2002). Benefits of moderate training to the nonspecific immune response of colts. Equine Vet. J., 34 (Suppl.): $182-185$.

E s cr i b a no B.M., C a s tejón F.M., Vivo R., S a n t is teban R., A gủ er a E.I., Rubio M.D. (2005). Effects of training on phagocytic and oxidative metabolism of peripheral neutrophils in horses exercised in the aerobic-anaerobic transition area. Vet. Res. Commun., 29: 149-158.

E sk a n d ar i F., S ter n b e r g E.M. (2002). Neural-immune interactions in health and disease. Ann. N. Y. Acad. Sci., 966: 20-27.

Fazio E., Medica P., Cravana C., Molinari P., Ferlazzo A. (2014). Effect of experience on adrenocortical and thyroid responses of Arabian horses to gymkhana games. J. Equine Vet. Sci., 34: 799-804.

F in n o C.J., M c K e n z i e E., Va 1 b e r g S.J., P a g a n J. (2010). Effect of fitness on glucose, insulin and cortisol responses to diets varying in starch and fat content in Thoroughbred horses with recurrent exertional rhabdomyolysis. Equine Vet. J., 38 (Suppl.): 323-328.

Fols om R.W., Littlefield-Chabaud M.A., French D.D., Pourciau S.S., Mistric L., Hor ohov D.W. (2001). Exercise alters the immune response to equine influenza virus and increases susceptibility to infection. Equine Vet. J., 33: 664-669.

F o r sli d J., H e d J. (1982). In vitro effect of hydrocortisone on the attachment and ingestion phases of immunoglobulin $\mathrm{G}$ and complement $3 \beta$-mediated phagocytosis by human neutrophils. Infect. Immun., 38: 811-816.

F r a p e D. (2010). Equine nutrition and feeding. Oxford, UK, John Wiley \& Sons Ltd., 4th ed.

Gorga s s e r I., Ti ch y A., P a $1 \mathrm{~m}$ e R. (2007). Faecal cortisol metabolites in Quarter Horses during initial training under field conditions. Vet. Med. Austria / Wien. Tierärztl. Mschr., 94: 226-230.

H in ch cliff K.W., Kan ep s A.J., Ge or R.J. (2008). Equine exercise physiology: The science of exercise in the athletic horse. Elsevier Health Sciences, Edinburgh, New York, p. 283.

H in e s M.T., S c h ot t II H.C., B a y ly W.M., L e r o u x A.J. (1996). Exercise and immunity: review with emphasis on the horse. J. Vet. Intern. Med., 10: 280-289.

Horohov D.W., Dimock A., Guirnalda P., Folsom R.W., McKeever K.H., Malin ow sk i K. (1999). Effect of exercise on the immune response of young and old horses. Am. J. Vet. Res., 60: 643-647.

Houpt K., Houpe T.R., Johns on J.L., Erb H.N., Yeon S.C. (2001). The effect of exercise deprivation on the behaviour and physiology of straight stall confined pregnant mares. Anim. Welf., 10: $257-267$.

Hу у р р ӓ S. (2005). Endocrinal responses in exercising horses. Livest. Prod. Sci., 92: 113-121.

Ivers en P.O., S tok land A., R ols tad B., B e nest ad H.B. (1994). Adrenaline-induced leu- 
kocytosis: recruitment of blood cells from rat spleen, bone marrow and lymphatics. Eur. J. Appl. Physiol., 68: 219-227.

Jensen-Waern M., Lindberg A., Johannisson A., Grondahl G., Lindgren J.A., E s s e n-Gu st a v s s on B. (1999). The effects of an endurance ride on metabolism and neutrophil function. Equine Vet. J., 30 (Suppl.): 605-609.

Jimenez M., Hinchcliff K.W., F arris J.W. (1998). Catecholamine and cortisol responses of horses to incremental exertion. Vet. Res. Commun., 22: 107-118.

Kędzierski W., Strze le c K., Cywińska A., Kowalik S. (2013). Salivary cortisol concentration in exercised thoroughbred horses. J. Equine Vet. Sci., 33: 1106-1109.

Korhonen P.A., Lilius E.M., Hy y pä S., Räsänen L.A., Pösö A.R. (2000). Production of reactive oxygen species in neutrophils after repeated bouts of exercise in Standard bred trotters. J. Vet. Med. A, 47: 565-573.

Krumrych W. (2006). Variability of clinical and haematological indices in the course of training exercise in jumping horses. Bull. Vet. Inst. Pulawy, 50: 391-396.

K rumry ch W., Wiśn i e w ski E. (2006). Influence of selected stimulators on chemiluminescence of peripheral blood neutrophils in horses. Med. Weter., 62: 204-206.

Lew i cki R., Tchórzewski H., Denys A., Kowalska M., Golińska A. (1987). Effect of physical exercise on some parameters of immunity in conditioned sportsmen. Int. J. Sports Med., 8: 309-314.

Lind en A., A rt T., A mory H., D e s me ch t D., L e ke ux P. (1991). Effect of 5 different types of exercise, transportation and ACTH administration on plasma cortisol concentration in sport horses. Equine Exercise Physiol., 3: 391-396.

Malinowski K., Shock E.J., Rochelle P., Kearns C.F., Guirnalda P.D., McKeever K.H. (2006). Plasma beta-endorphin, cortisol and immune responses to acute exercise are altered by age and exercise training in horses. Equine Vet. J., 36 (Suppl.): 267-273.

Marc M., P arvizi N., Elle nd orff F., Kallwe it E., Els a e s ser F. (2000). Plasma cortisol and ACTH concentrations in the warmblood horse in response to a standardized treadmill exercise test as physiological markers for evaluation of training status. J. Anim. Sci., 78: 1936-1946.

Mc Carthy D.A., Dale M.M. (1988). The leucocytosis of exercise. A review and model. Sports Med., 6: 333-363.

M c K e e ver K.H. (2003). Aging and how it affects the physiological response to exercise in the horse. Clin. Tech. Equine Pract., 2: 258-265.

M ir c e an M., Gi urg i u G., M ir c e an V., Z inveli u E. (2007). Serum cortisol variation of sport horses in relation with the level of training and effort intensity. Bull. USAMV-CN, 64: 488-492.

M i y a sh iro P., M i chim a L.E.S., B o n o mo C.C.M., F e rn and es W.R. (2012). Plasma cortisol level attributable to physical exercise in endurance horses. Ars. Vet. Jaboticabal., 28: 85-89.

N a chreiner R., Re fs a 1 K.R., Rick M., Mazaki - Tovi M., S is t M.D. (2015). Endocrinology reference ranges. Diagnostic Center for Population \& Animal Health, Michigan State University.

N a g a t a S., Take d a F., Kuros a w a M., H ir a g a A., Ka i M., T a y a K. (1999). Plasma adrenocorticotropin, cortisol and catecholamines response to various exercise. Equine Vet. J. 30 (Suppl.): $570-574$.

Nogueira G.P., Barnabe R.C., Bedran de Castro J.C., Moreira A.F., Fernand e s W.R., Mir a nd ol a R.M.S., H ow ard D.L. (2002). Serum cortisol, lactate and creatinine concentrations in Thoroughbred fillies of different ages and states of training. Braz. J. Vet. Res. Anim. Sci., 39: 54-57.

Pedersen B.K., H of f m a n-Go et z L. (2000). Exercise and the immune system: regulation, integration, and adaptation. Physiol. Rev., 80: 1055-1081.

P e e ter s M., Clos s on C., B e cker s J.F., Vand e n he ede M. (2013). Rider and horse salivary cortisol levels during competition and impact on performance. J. Equine Vet. Sci., 33: 155-160.

P y n e D.B. (1994). Regulation of neutrophils function during exercise. Sports Med., 17: 245-258.

R a id a 1 S.L., L o ve D.N., B a i l e y G.D., R o s e R.J. (2000). Effect of single bouts of moderate and high intensity exercise and training on equine peripheral blood neutrophil function. Res. Vet. Sci., 68: $141-146$.

R e i c hli in S. (1993). Neuroendocrine-immune interactions. N. Engl. J. Med., 329: 1246-1242. 
Robson P.J., A lston T.D., Myburgh K.H. (2003). Prolonged suppression of the innate immune system in the horse following an $80 \mathrm{~km}$ endurance race. Equine Vet. J., 35: 133-137.

Robs on P.J., B lann in A.K., Wals h N.P., C a s t e 11 L.M., G l e e s on M. (1999). Effects of exercise intensity, duration and recovery on in vitro neutrophil function in male athletes. Int. J. Sports Med., 20: 128-135.

R o s s d a le P.D., Burguez P.N., C a sh R.S.G. (1982). Changes in blood neutrophils/lymphocyte ratio related to adrenocortical function in the horse. Equine Vet. J., 14: 293-298.

$\mathrm{S}$ a b e v S. (2011). Effect of the jumping activity in the course of training exercise on the level of serum cortisol, blood lactate and heart rate in horses. Trakia J. Sci., 9: 78-82.

Shinka i S., Wat a nabe S., A s a i H., She k P.N. (1996). Cortisol response to exercise and post exercise suppression of blood lymphocyte subset counts. Int. J. Sports Med., 17: 597-603.

S m i th J.A., Te 1 ford R.D., M a s o n I.B., We i d e m a n n M.J. (1990). Exercise, training and neutrophil microbicidal activity. Int. J. Sports, 11: 179-187.

Strzelec K., K a n k of er M., Pi etrzak S. (2011). Cortisol concentration in the saliva of horses subjected to different kinds of exercise. Acta Vet. Brno, 80: 101-105.

Suzuki K., Totsuka M., Nakaji S., Yamada M., Kudoh S., Liu Q., Sugawara K., Y a m a y a K., S a to K. (1999). Endurance exercise causes interaction among stress hormones, cytokines, neutrophil dynamics, and muscle damage. J. Appl. Physiol., 87: 1360-1367.

$\mathrm{S} z$ a frán s k a B., Z i ę c i k A., O kr a s a S. (2002). Primary antisera against selected steroids or proteins and secondary antisera against $\gamma$-globulins - an available tool for studies of reproductive processes. Reprod. Biol., 2: 187-204.

Thornton J. (1985). Hormonal responses to exercise and training. Vet. Clin. North. Am. Equine Pract., 1: 477-496.

Toutain P.L., Las sourd V., Popot M.A., Laroute V., Alvinerie M., Bonnaire Y. (1995). Urinary cortisol excretion in the resting and exercising horse. Equine Vet. J., 27: 457-462.

Vincze A., Szabó Cs., Heves i A., Veres S., Ü tö D., B a b ins zk y L. (2010). Effect of age and event on post exercise values of blood biochemical parameters in show jumping horses. Acta Agr. Kapos., 14: 185-191.

Wong C.W., S mith S.E., Thong Y.H., Opdebeeck J.P., Thornton J.R. (1992). Effects of exercise stress on various immune functions in horses. Am. J. Vet. Res., 53: 1414-1417.

Received: 3 XI 2016

Accepted: 11 VII 2017 